\title{
Is there a role for consolidative radiotherapy in the treatment of aggressive and localized Non-Hodgkin Lymphoma? A systematic review with meta-analysis
}

Lucas Vieira dos Santos ${ }^{1,2}$, João Paulo da Silveira Nogueira Lima ${ }^{1,2}$, Carmen Sílvia Passos Lima ${ }^{3}$, Emma Chen Sasse ${ }^{2}$ and André Deeke Sasse $e^{2,3^{*}}$

\begin{abstract}
Background: Chemotherapy is the mainstay of non-Hodgkin lymphoma (NHL) treatment. Based on expert opinion, the use of radiotherapy (RT) is currently preferred in some institutions as consolidative treatment for patients with localized disease. The lack of conclusive data coming from conflicting studies about the impact of treatment demands a systematic review, which could provide the most reliable assessment for clinical decision-making. We evaluate the addition of RT post-CT, for aggressive and localized NHL (ALNHL).

Methods: Randomized controlled trials (RCT) that evaluated chemotherapy alone versus chemotherapy plus RT were searched in databases. The outcomes were overall survival (OS), progression-free survival (PFS), overall response rate (ORR) and toxicity. Risk ratio (RR) and hazard ratio (HR) with their respective $95 \%$ confidence intervals (Cl) were calculated using a fized-effect model.

Results: Four trials (1,796 patients) met the inclusion criteria. All trials tested the use of RT after systemic therapy comprising anthracycline-based chemotherapy. This systematic review showed that RT enhances PFS after chemotherapy (hazard ratio [HR] 0.81;95\% Cl 0.67-0.98; $p=0.03$ ), with no impact on ORR and OS. Some heterogeneity between trials could limit the conclusions about OS. Toxicity data could not be pooled due to differences in reporting adverse events.

Conclusions: This systematic review with meta-analysis shows no improvement in survival when adding RT to systemic therapy for ALNHL. Our conclusions are limited by the available data. Further evaluations of new RT technologies and its association with biologic agents are needed.
\end{abstract}

Keywords: Non-Hodgkin lymphoma, Consolidative radiotherapy, Meta-analysis, Systematic review

\section{Background}

Non-Hodgkin lymphoma (NHL) is the sixth most common cause of cancer death in the world [1]. About 300,000 new cases of NHL occur every year, accounting for nearly $3 \%$ of all new cases of cancer. Among them, more than half will die due to NHL [2].

\footnotetext{
* Correspondence: sasse@cevon.com.br

${ }^{2}$ CEVON - Centro de Evidências em oncologia, Universidade Estadual de Campinas, UNICAMP, Campinas, Brazil

${ }^{3}$ Departamento de Clínica Médica, Centro de Evidências em Oncologia - CEVON, Faculdade de Ciências Médicas, Universidade Estadual de Campinas - UNICAMP, Campinas, SP CEP 13083-970, Brazil

Full list of author information is available at the end of the article
}

There are several classifications currently in use for NHL that are somewhat overlapping. The Revised European American Lymphoma (REAL) classification [3] was initially proposed. However, a REAL-based classification is now widely accepted, also known as the World Health Organization (WHO) classification for hematologic malignancies. This classification is based on cell of origin, maturity, morphology, immunophenotype, genetic and clinical features [4]. Considered outdated by many, the International Working Formulation [5] (WF) had divided NHL in low, intermediate and high grade, based on morphology and natural history. It remains important

\section{Biomed Central}


because studies designed more than 10 years ago were based on this classification.

In some series, more than one third of patients with NHL have an aggressive phenotype. For patients with localized disease, radiotherapy (RT) was the first curative approach and continues to be a part of combined modality therapy [6-8]. Previous studies have shown that almost $70 \%$ of patients with localized NHL can be cured by RT alone $[9,10]$. However, the high relapse rate outside the radiation field justifies the requirement of chemotherapy in this setting $[11,12]$.

Since the early 1980s, the synergistic effect of both modalities has been evaluated, and their combination widely advocated in the treatment of patients with NHL [13-17]. The benefit of this strategy was first shown in a randomized trial including 316 patients, comparing RT versus chemotherapy versus combined therapy [18]. In this trial, the combination arm had better failure-free survival and OS when compared to chemotherapy alone, or RT alone arms. The use of RT after systemic therapy is frequently recommended, based on expert opinion, to improve local control of the disease, and possibly to diminish relapse and death [19].

The lack of conclusive data coming from conflicting studies about the impact of treatment demands a systematic review, which could provide the most reliable assessment for clinical decision-making. The aim of this systematic review is to assess whether adding RT to standard chemotherapy for aggressive and localized NHL (ALNHL) has an impact on local tumor control and survival.

\section{Methods}

This study was approved by the Ethics Committee at Universidade Estadual de Campinas.

\section{Types of studies}

Randomized controlled trials (RCT) were included comparing chemotherapy and consolidative RT versus chemotherapy alone for patients with ALNHL.

\section{Types of participants}

Participants included adults with ALNHL, without previous treatment. We defined localized disease as Ann Arbor stage I and stage II with contiguous disease encompassed by a radiation field [20]. We defined aggressive NHL according to the WF [5], the REAL classification [3], or the WHO classification [4]. In older trials, an intermediate or a high-grade classification was permitted.

\section{Types of outcome measures}

The primary outcome was OS. Secondary outcomes of interest were PFS, response to therapy and safety. PFS encompassed the term disease-free survival (DFS), used when there was no residual disease.

\section{Search strategies for identification of studies}

We performed an electronic database search [21] in MEDLINE, EMBASE, Cochrane Central Register of Controlled Trials - CENTRAL and LILACS (until January 2010); electronic or hand searching of the conference proceedings between 1980 and 2009 of the American Society of Clinical Oncology (ASCO), the American Society for Therapeutic Radiology and Oncology (ASTRO), the American Society of Hematology (ASH), the European Conference on Clinical Oncology (ECCO) and the European Society of Medical Oncology (ESMO). Reference list of all recovered trials and relevant reviews were also considered. For electronic databases, we used a sensitive search strategy with words linked to NHL and RT.

\section{Trial selection}

Titles and abstracts of studies identified from search strategy were screened independently by two reviewers (LVS and JPL), according to the eligibility criteria described above. Disagreements in the trial selection were resolved by discussion and a third reviewer was invited to give his opinion (ADS) if consensus was not reached. Full-text versions of all eligible studies were obtained for quality assessment and data extraction.

\section{Quality assessment}

The quality of each individual study was assessed independently by two reviewers (LVS and ADS) using the published manuscript. A specific data extraction form was designed for assessment of quality features of studies, such as randomization, allocation concealment, intentionto-treat principle, similarity of treatment arms according to known prognostic factors, follow up and drop-outs $[22,23]$. Disagreements were discussed among the group until consensus was reached.

\section{Data extraction}

A data extraction form was designed previously, and included the following items: general identification information (authors, title, journal, date of publication, protocol name, and duplication of publication), trial, type of patients, intervention characteristics, and reported outcomes. Data extraction was performed independently by two reviewers (LVS and JPL) and disagreements were resolved by consensus. When it was not possible to obtain data from the published trial, we tried to contact the authors to provide the information or additional data.

Data were directly extracted from the published data, or estimated from survival curves using the methods described by Parmar and colleagues [24]. Calculations 


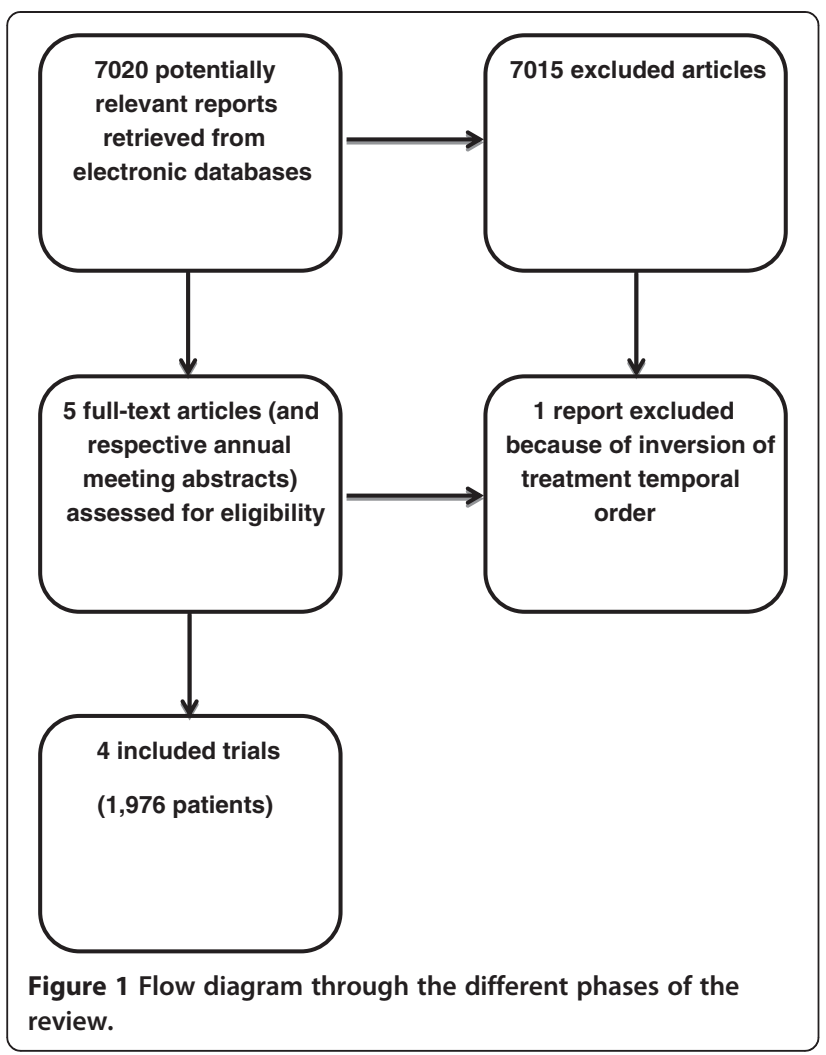

were carried out using the spreadsheet provided by Tierney and colleagues [25].

\section{Statistical analysis and synthesis}

Details regarding the main methodological dimensions empirically linked to bias as described by Deeks and colleagues [26] were extracted and the methodological quality of each selected trial was assessed by two reviewers (LVS and ADS). Special attention was given to the generation and concealment of the sequence of randomization, whether an intention-to-treat analysis was performed or not, and source of funding. These data were applied in sensitivity analyses to test the stability of the results.

Review Manager 5 software (RevMan 5; The Nordic Cochrane Centre, The Cochrane Collaboration, Copenhagen, Denmark) was used to perform the meta-analysis. For time-to-event variables, the effect of the treatment for each single study was expressed as a hazard ratio
(HR) of chemotherapy plus RT arm over the chemotherapy alone arm. The 95\% confidence interval (CI) was calculated for each point estimate. For dichotomous variables, the effect of treatment was calculated as a risk ratio (RR), and presented with the correspondent 95\% CI. Data were analyzed using Mantel-Haenszel fixedeffect method.

Statistical heterogeneity of the results of the trials was assessed by the chi-square test [27], expressed with the $\mathrm{I}^{2}$ index, as described by Higgins and colleagues [28]. When heterogeneity was detected, a possible explanation for it was intensively pursued. If a reasonable cause was found, a separate analysis was then performed. When the cause was not apparent and heterogeneity was caused by divergent data in terms of direction of results, we chose not to pool the data. Publication bias was evaluated by the Egger test $[29,30]$.

\section{Results}

\section{Description of studies and quality assessment}

Four trials with a total of 1,796 patients met the inclusion criteria (Figure 1) [31-35]. One study was excluded because RT was employed before chemotherapy in the combined modality arm [18]. All data were extracted from the original peer-reviewed publication. There was no evidence of publication bias (Egger's test: $\mathrm{p}=0.52$ ). The methodological characteristics of the selected trials included in this meta-analysis (Table 1) had no impact on the results obtained, as confirmed by the sensitivity analysis performed [this data is available upon request].

All trials tested the use of RT after systemic therapy comprising anthracycline-based chemotherapy (Table 2). Treatment with cyclophosphamide, doxorubicin, vincristine and prednisone (CHOP) was the preferred regimen in these trials.

The Southwest Oncology Group (SWOG) 8736 trial [32] included 401 patients with intermediate- or highgrade NHL. Stages I and II were allowed, except those with stage II and bulky disease. Participants were randomized to receive 8 cycles of CHOP or 3 cycles of CHOP plus involved-field radiation therapy (IFRT) with doses of 40 to $55 \mathrm{~Gy}$. The trial was designed to address if the addition of RT may allow the use of less cycles of chemotherapy. Approximately $20 \%$ of the patients had two or more risk factors (international prognostic index

Table 1 Main characteristics of selected trials related to biasTrial

\begin{tabular}{|c|c|c|c|c|c|c|c|c|c|}
\hline & $\begin{array}{l}\text { Year of } \\
\text { Publication }\end{array}$ & $\begin{array}{l}\text { Random } \\
\text { Assignment }\end{array}$ & $\begin{array}{l}\text { Allocation } \\
\text { Concealment }\end{array}$ & $\begin{array}{l}\text { Withdrawn } \\
\text { Description }\end{array}$ & a-error & $\beta$-error & ITT & Site & Sponsor \\
\hline SWOG 8736 & 1998 & Adequate & Unclear & Yes & No & No & Yes & Multicentric & Public \\
\hline ECOG 1484 & 2004 & Adequate & Adequate & Yes & Yes & Yes & Yes & Multicentric & Public \\
\hline GELA LNH 93-1 & 2005 & Adequate & Adequate & No & Yes & Yes & Yes & Multicentric & Both \\
\hline GELA LNH 93-4 & 2007 & Adequate & Adequate & No & Yes & Yes & Yes & Multicentric & Both \\
\hline
\end{tabular}


Table 2 Study population and therapy

\begin{tabular}{|c|c|c|c|c|c|c|c|c|}
\hline Trial & Arms & $N$ & Population & Age and PS 0-1 & Stage & LDH & IPI & RT \\
\hline \multirow[t]{2}{*}{ SWOG 8736} & $\mathrm{CHOP} \times 8$ & 201 & \multirow{2}{*}{$\begin{array}{l}\text { WF groups D-J (DLBCL 75\%); } \\
\text { stage I to II non-bulky }\end{array}$} & $>60 y=49 \% 0-1=96 \%$ & || 33\% & $\uparrow 19 \%$ & $0-1=71 \%$ & No RT \\
\hline & $\mathrm{CHOP} \times 3+\mathrm{RT}$ & 200 & & $>60 y=50 \% 0-1=97 \%$ & || $32 \%$ & $\uparrow 20 \%$ & $0-1=74 \%$ & IFRT 40-55 Gy \\
\hline \multirow[t]{2}{*}{ ECOG 1484} & $\mathrm{CHOP} \times 8$ & 112 & \multirow{2}{*}{$\begin{array}{l}\text { WF H-J (DLBCL } 83 \%) \text {; } \\
\text { stage I bulky to Il; complete responders to CHOP only }\end{array}$} & Median 60y 0-1 = 93\% & \| 70\% E 52\%, B20\% & NA & $N R$ & No RT \\
\hline & $\mathrm{CHOP} \times 8+\mathrm{RT}$ & 103 & & Median 58y 0-1 = 96\% & || 68\% E 45\% B22\% & NA & NR & IFRT 30 Gy \\
\hline \multirow[t]{2}{*}{ GELA LNH 93-1 } & $\mathrm{ACVBP}+\mathrm{CT}$ & 318 & \multirow{2}{*}{$\begin{array}{l}\text { WF H-J or anaplastic according to UKC (DLBCL 81\%); } \\
15-60 y ; \text { aalPI = 0t; stages I to II }\end{array}$} & Median 46y 0-1 = 100\% & || 32\% E 46\% & $\uparrow 3 \%$ & $0=96 \% \dagger$ & No RT \\
\hline & $\mathrm{CHOP} \times 3+\mathrm{RT}$ & 329 & & Median 47y 0-1 $=100 \%$ & \| 32\% E 52\% & $\uparrow 3 \%$ & $0=95 \% \dagger$ & IFRT $40 \mathrm{~Gy}$ \\
\hline \multirow[t]{2}{*}{ GELA LNH 93-4 } & $\mathrm{CHOP} \times 4$ & 277 & \multirow{2}{*}{$\begin{array}{l}\text { WF H-J or anaplastic according to UKC (DLBCL 80\%); } \\
>60 y \text {; aalPI = 0t; stages I to II }\end{array}$} & Median 69y 0-1 = 99\% & || 32\% Bu 8\% & $\uparrow 2 \%$ & $0=95 \% \dagger$ & No RT \\
\hline & $\mathrm{CHOP} \times 4+\mathrm{RT}$ & 299 & & Median 68y 0-1 = 99\% & || 34\% Bu 9\% & $\uparrow 3 \%$ & $0=95 \% \dagger$ & IFRT 40 Gy \\
\hline
\end{tabular}

Abbreviations: ACVBP +CT: doxorubicin $75 \mathrm{mg} / \mathrm{m}^{2} \mathrm{D} 1+$ cyclophosphamide $1200 \mathrm{mg} / \mathrm{m}^{2} \mathrm{D} 1+$ vindesine $2 \mathrm{mg} / \mathrm{m}^{2} \mathrm{D} 1,5+$ bleomycin $10 \mathrm{mg}$ D1,5 and prednisone $60 \mathrm{mg} / \mathrm{m}^{2} \mathrm{D} 1-5,3 \mathrm{cycles}$ with 14 days each and then consolidative chemotherapy with methotrexate, folinic acid, etoposide, ifosfamide and cytarabine; B: "B" symptoms; Bu: bulky disease; CHOP: cyclophosphamide $750 \mathrm{mg} / \mathrm{m}^{2} \mathrm{D} 1+$ doxorubicin $50 \mathrm{mg} / \mathrm{m}^{2} \mathrm{D} 1+\mathrm{vincristine}$ $1,4 \mathrm{mg} / \mathrm{m}^{2}$ D 1 + prednisone $60 \mathrm{mg} / \mathrm{m}^{2}$ or $100 \mathrm{mg}$ D1-5, 21 day cycles; DLBCL: diffuse large B cell lymphoma; E: extranodal disease; IFRT: involved-field radiotherapy; IPI: International Prognostic Index; LDH: lactate dehydrogenase; NA: not available; NR: not reported; uKC: updated Kiel Classification; WF: Working Formulation; + age-adjusted IPI. 
$[$ IPI] $\geq 2$ ) [36]. Complete response occurred in $73 \%$ of chemotherapy patients, and in $75 \%$ of chemotherapy plus RT patients. With a median follow-up of 4.4 years, five-year PFS was $64 \%$ for CHOP x 8, and $77 \%$ for CHOP x 3 plus RT $(p=0.03)$. Five-year OS was $72 \%$ and $82 \%(\mathrm{p}=0.02)$, respectively. In an updated analysis, the results showed an excess of late relapses and deaths due to lymphoma in the combined-modality treatment. PFS and OS curves of the two arms overlapped at 7 and 9 years, respectively [33]. Unfortunately, it was impossible to use these updated results in meta-analysis, due to lack of extractable data.

The ECOG 1484 trial [34] included patients with a less favorable prognosis. All patients had at least bulky or extranodal disease, most of them were in stage II, and only high-grade NHL was allowed. This study included 352 patients receiving 8 cycles of $\mathrm{CHOP}$. Those who achieved complete response (61\%) were randomized to receive involved field radiation treatment (IFRT) with doses of 30 Gy $(n=103)$ or observation $(n=112)$. There were imbalances between groups, with patients allocated to receive RT presenting more mediastinal involvement and bulky disease. Six-year DFS was $53 \%$ for observation and $69 \%$ for RT $(\mathrm{p}=.05)$, and six-year OS rates were $67 \%$ and $79 \%(\mathrm{p}=.23)$, respectively. The trial was designed to detect a $20 \%$ improvement in two-year DFS using a one-sided significance test. Thus, the sample size was not adequate to detect a survival advantage of consolidative RT.

In the Groupe d'Etudes des Lymphomes de l'Adulte (GELA) LNH 93-1 trial [31], 647 patients with ALNHL under 60 years and without age-adjusted IPI risk factors [36] (ECOG-PS $<2$ and normal lactate dehydrogenase $[\mathrm{LDH}])$ were randomized to receive an intensified induction chemotherapy (ACVBP) and a consolidative chemotherapy regimen or 3 cycles of $\mathrm{CHOP}$ plus 40 Gy IFRT. Bulky disease was present in $11 \%$ of patients and extranodal involvement in 50\%. Complete response rate was 93\% for chemotherapy alone and $92 \%$ for combined modality treatment. Five-year PFS was $82 \%$ for ACVBP versus $74 \%$ for CHOP plus RT $(\mathrm{p}<0.001)$. Five-year OS was $90 \%$ and $81 \%$, respectively $(\mathrm{p}=0.001)$.
The GELA LNH 93-4 trial [35] randomized 576 patients older than 60 with ALNHL and without ageadjusted IPI risk factors [36] to receive 4 cycles of CHOP alone or 4 cycles of CHOP plus 40 Gy IFRT. Bulky disease was present in $9 \%$ of patients and extranodal involvement in $48 \%$. Accrual was interrupted earlier due to increasing evidence that rituximab could improve efficacy in patients with aggressive NHL $[37,38]$. With a median follow-up of 7 years, 5 -year PFS was $61 \%$ for $\mathrm{CHOP}$ alone and $64 \%$ for $\mathrm{CHOP}$ plus $\mathrm{RT}$ $(\mathrm{p}=0.56)$, and 5 -year OS was $72 \%$ and $68 \%$, respectively $(\mathrm{p}=0.54)$.

\section{Effects of interventions \\ Response rate}

There were divergences in the definition of response assessments across, but not within trials. Unconfirmed complete response was analyzed as complete response in GELA trials [31,35]. Only complete responders could be randomized to receive RT or observation in the ECOG 1484 trial [34]. SWOG 8736 [32,33] described only complete response, so data could not be used for overall response rate evaluation. Data from 1,198 patients were available. Response was analyzed according to assessable patients, as reported in these RCT. Overall response rates (ORR) were not different between groups (RR 0.98; 95\% CI $0.95-1.02 ; \mathrm{p}=0.33)$, with no heterogeneity between trials $\left(\mathrm{p}=0.53 ; \mathrm{I}^{2}=0 \%\right)$ (Figure 2). Data from 1,483 patients could be pooled for complete response rate (RR 1.01; 95\% CI 0.97-1.04; $\mathrm{p}=0.76$ ), with no heterogeneity among trials $\left(\mathrm{p}=0.46 ; \mathrm{I}^{2}=0 \%\right)$ (Figure 3 ).

\section{Progression-free survival}

Four trials comprising 1,796 patients were analyzed for PFS [31,32,34,35]. Data from the ECOG 1484 trial [34] could not be obtained for an intention-to-treat analysis due to insufficient data. Thus, estimation was made from the published disease-free survival curve from per-protocol patients. Data from all four trials could not be pooled due to heterogeneity among them $\left(\mathrm{p}=0.0001 ; \mathrm{I}^{2}=86 \%\right)$. The heterogeneity persisted even excluding trials without intention-to-treat data $(\mathrm{p}=0.0002$;

\begin{tabular}{|c|c|c|c|c|c|c|c|}
\hline \multirow[b]{2}{*}{ Study or Subgroup } & \multicolumn{2}{|c|}{ CT plus RT } & \multicolumn{2}{|c|}{ CT alone } & \multirow[b]{2}{*}{ Weight } & \multirow{2}{*}{$\begin{array}{l}\text { Risk Ratio } \\
\text { M-H, Fixed, } 95 \% \mathrm{Cl}\end{array}$} & \multirow{2}{*}{$\begin{array}{c}\text { Risk Ratio } \\
\text { M-H, Fixed, 95\% Cl } \\
\end{array}$} \\
\hline & Events & Total & Events & Total & & & \\
\hline GELA LNH 93-1 & 298 & 321 & 294 & 309 & $53.4 \%$ & $0.98[0.94,1.01]$ & \\
\hline GELA LNH 93-4 & 271 & 295 & 252 & 273 & $46.6 \%$ & $1.00[0.95,1.04]$ & \\
\hline Total $(95 \% \mathrm{Cl})$ & & 616 & & 582 & $100.0 \%$ & $0.98[0.95,1.02]$ & 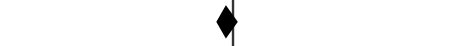 \\
\hline Total events & 569 & & 546 & & & & \\
\hline $\begin{array}{l}\text { Heterogeneity: } \mathrm{Chi}^{2}= \\
\text { Test for overall effect: }\end{array}$ & $\begin{array}{l}39, \mathrm{df}=1 \\
=0.97(\mathrm{P}\end{array}$ & $\begin{array}{l}(P=0 \\
=0.33\end{array}$ & $53) ; 1^{2}=$ & $0 \%$ & & & 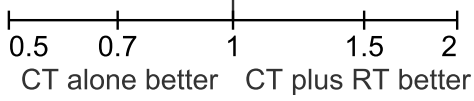 \\
\hline
\end{tabular}




\begin{tabular}{|c|c|c|c|c|c|c|c|}
\hline Study or Subgroup & \multicolumn{2}{|c|}{ CT plus RT } & \multicolumn{2}{|c|}{ CT alone } & Weight & $\begin{array}{l}\text { Risk Ratio } \\
\text { M-H, Fixed, } 95 \% \mathrm{Cl}\end{array}$ & $\begin{array}{c}\text { Risk Ratio } \\
\text { M-H, Fixed, } 95 \% \mathrm{Cl}\end{array}$ \\
\hline GELA LNH 93-1 & 294 & 321 & 288 & 309 & $45.1 \%$ & $0.98[0.94,1.03]$ & \\
\hline GELA LNH 93-4 & 270 & 295 & 244 & 273 & $39.0 \%$ & $1.02[0.97,1.08]$ & \\
\hline SWOG 8736 & 106 & 142 & 104 & 143 & $15.9 \%$ & $1.03[0.89,1.18]$ & \\
\hline Total $(95 \% \mathrm{Cl})$ & & 758 & & 725 & $100.0 \%$ & $1.01[0.97,1.04]$ & \\
\hline Total events & 670 & & 636 & & & & \\
\hline $\begin{array}{l}\text { Heterogeneity: } \mathrm{Chi}^{2}= \\
\text { Test for overall effec }\end{array}$ & $\begin{array}{l}.55, \mathrm{df}=2 \\
z=0.31(\mathrm{~F}\end{array}$ & $\begin{array}{l}(P=0 . \\
=0.76\end{array}$ & $46) ; 1^{2}=$ & $0 \%$ & & & $\begin{array}{ccccc}0.5 & 0.7 & 1 & 1.5 & 2 \\
\text { CT alone better } & \text { CT plus RT better }\end{array}$ \\
\hline
\end{tabular}

$\mathrm{I}^{2}=88 \%$ ) [34]. The GELA LNH 93-1 trial [31] seemed to be the main cause of heterogeneity, maybe due to considerable differences in intensity and duration of systemic therapy in both arms. Excluding the GELA LNH 93-1 trial [31], PFS was longer for combined-modality treatment (HR 0.81; 95\% CI 0.67-0.98; $\mathrm{p}=0.03$ ), with an acceptable heterogeneity among trials $(\mathrm{p}=0.03$; $\mathrm{I}^{2}=35 \%$ ) (Figure 4).

Pooling data from trials whose arms had the same chemotherapy regimen (791 patients) [34,35] showed that the addition of RT to systemic therapy resulted in no improvement in PFS (HR 0.86; 95\% CI 0.69-1.06; $\mathrm{p}=0.16$ ). In this analysis, it was not possible to exclude heterogeneity among trials $\left(\mathrm{p}=0.17 ; \mathrm{I}^{2}=46 \%\right)$.

\section{Overall survival}

Again, data from ECOG 1484 trial [34] could not be obtained for an intention-to-treat analysis due to lack of an adequate description of results. Thus, estimation was made from the published overall survival (OS) curve from "as treated" patients. Although all trials $[31,32,34,35]$ reported data of survival analysis comprising 1,796 patients, results from four trials could not be pooled due to heterogeneity among them $(\mathrm{p}=0.0009$; $\left.\mathrm{I}^{2}=82 \%\right)$. Even excluding the ECOG 1484 trial, there was still heterogeneity detected among trials $(\mathrm{p}=0.0009$; $\mathrm{I}^{2}=86 \%$ ). The GELA LNH 93-1 trial [31] seemed to be mainly responsible for the heterogeneity, again, possibly due to considerable differences in intensity and duration between systemic therapy in both arms. However, even excluding the GELA LNH 93-1 trial [31], we could still detect heterogeneity among trials $\left(p=0.04 ; \mathrm{I}^{2}=68 \%\right)$.

Pooling data only from the studies whose arms had the same chemotherapy regimen [34,35], the addition of RT showed no improvement in OS (HR 1.00; 95\% CI $0.79-1.26 ; \mathrm{p}=0.99)$. Even in this analysis, there was considerable heterogeneity among trials $\left(\mathrm{p}=0.15 ; \mathrm{I}^{2}=51 \%\right)$.

\section{Toxicity}

In the SWOG 8736 trial [32] there were no differences in life-threatening toxicity or death between chemotherapy alone and chemotherapy plus RT arms (30\% and $40 \% ; \mathrm{p}=0.06$; one death in each arm). Patients assigned to chemotherapy alone arm had more congestive heart failure than patients assigned to chemotherapy plus RT arm. More patients in the chemotherapy alone arm did not complete the assigned regimen (28 and 3 patients, respectively, $\mathrm{p}<0.01)$.

In the ECOG 1484 trial [34], toxicity was described according to the phase of therapy (chemotherapy and then RT or observation). There was only one grade 4 adverse event (thrombocytopenia) in the RT arm and none in the observation arm. GELA LNH 93-1 [31] and 93-4 [35] did not describe toxicity individually for each arm, but life-threatening toxicity appeared to occur in a small number of patients.

Due to differences in reporting adverse events, it was not feasible to pool toxicity data. Radiation therapy appeared to be well tolerated, with side effects dependent mainly on the location of disease.

\begin{tabular}{|c|c|c|c|c|c|c|c|c|c|c|}
\hline Study or Subgroup & $\begin{array}{l}\text { CT plus } \\
\text { Events }\end{array}$ & $\begin{array}{l}\text { RT } \\
\text { Total }\end{array}$ & $\begin{array}{l}\text { CT alo } \\
\text { Events }\end{array}$ & $\begin{array}{l}\text { ne } \\
\text { Total }\end{array}$ & O-E & Variance & Weight & $\begin{array}{c}\text { Hazard Ratio } \\
\text { Exp }[(\mathrm{O}-\mathrm{E}) / \mathrm{V}] \text {, Fixed, } 95 \% \mathrm{Cl}\end{array}$ & $\begin{array}{r}\text { Hazard } \\
\operatorname{Exp}[(\mathrm{O}-\mathrm{E}) / \mathrm{V}],\end{array}$ & $\begin{array}{l}\text { d Ratio } \\
\text { ], Fixed, } 95 \% \mathrm{Cl}\end{array}$ \\
\hline ECOG 1484 & 0 & 79 & 0 & 93 & -8.57 & 20.72 & $19.2 \%$ & $0.66[0.43,1.02]$ & $\square$ & \\
\hline GELA LNH 93-4 & 127 & 299 & 125 & 277 & -4.33 & 62.65 & $58.0 \%$ & $0.93[0.73,1.20]$ & & \\
\hline SWOG 8736 & 45 & 200 & 65 & 201 & -10.02 & 24.64 & $22.8 \%$ & $0.67[0.45,0.99]$ & & \\
\hline Total $(95 \% \mathrm{Cl})$ & & 578 & & 571 & & & $100.0 \%$ & $0.81[0.67,0.98]$ & & \\
\hline Total events & 172 & & 190 & & & & & & & \\
\hline \multicolumn{9}{|c|}{$\begin{array}{l}\text { Heterogeneity: } C \mathrm{Ch}^{2}=3.05, \mathrm{df}=2(\mathrm{P}=0.22) ; \mathrm{I}^{2}=35 \% \\
\text { Test for overall effect: } Z=2.21(P=0.03)\end{array}$} & 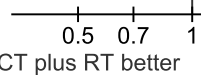 & $\begin{array}{l}1.5 \quad 2 \\
\text { CT alone better }\end{array}$ \\
\hline
\end{tabular}




\section{Risk of bias}

There was no evidence of publication bias (Egger's test: $\mathrm{p}=0.52$ ). The methodological characteristics of the selected trials included in this meta-analysis (described in Table 1) had no impact on the results obtained, as confirmed by the sensitivity analysis performed [this data is available upon request].

\section{Discussion}

Early stage aggressive NHL is a heterogeneous group of diseases with a high potential of cure. Systemic therapy has been the mainstream of therapy for more than 20 years. Additionally, RT had shown to increase regional control, which may lead to improvement in survival. Other possible secondary benefits of radiotherapy could be the diminishing of chemotherapy late effects.

Considering that relapses usually occur at the site of disease, and RT alone can cure up to $70 \%$ of patients, it seems rational to test $\mathrm{RT}$ after chemotherapy in patients with ALNHL. The achievement of local control could be, in this setting, a surrogate of survival improvement.

Since the publication of the SWOG 8736 trial [32], radiation therapy has become the standard therapy in North America. Unfortunately, the benefit of the treatment in prolonging PFS and OS has not been sustained over the years [33]. The ECOG 1484 trial [34] evaluated the addition of $\mathrm{RT}$ in patients with complete response with unfavorable results. In the trial, DFS (but not OS) was better in the combination arm. The GELA LNH 93-1 trial [31] compared short-course chemotherapy regimen plus RT to an intensified chemotherapy regimen. The group receiving the ACVBP regimen showed improved survival when compared to the group receiving CHOP for 8 cycles [39] for non-localized NHL or CHOP plus RT for localized disease [31]. Despite that, the more intensive regimen has not been widely accepted due to long term adverse events, like acute myelogenous leukemia, myelodysplastic syndrome and lung cancer [40]. This is especially important for patients with one IPI risk factor [36], in whom cure rates usually exceed $80 \%$ with CHOP-based chemotherapy [31,32]. Thus, some advocate ACVBP should not be considered a valid alternative to $C H O P$ in patients without high risk of recurrence. Recently, ACVBP plus rituximab (R-ACVBP) was compared to CHOP plus rituximab in young patients with advanced diffuse large B-cell lymphoma. With a median follow up of 44 months, R-ACVBP improved overall survival [41]. Long term follow up is needed to address long term adverse events.

Both the GELA LNH 93-1 [31] and SWOG 8736 $[32,33]$ trials suggested that radiotherapy cannot replace inadequate chemotherapy regimens. The GELA LNH 93-4 trial [35] evaluated the addition of RT to 4 cycles of $\mathrm{CHOP}$ in the treatment of elderly patients with
ALNHL. No improvements in terms of PFS or OS were observed. Five-year PFS in the chemotherapy alone arm was $61 \%$, comparable to $64 \%$ in the chemotherapy alone arm after 8 cycles of CHOP in the SWOG trial in younger patients with a more favorable prognosis [32].

This systematic review showed that RT could enhance PFS after chemotherapy, with no impact on ORR and OS. Heterogeneity among trials limits a definite conclusion. The interventions under study and trial design characteristics, such as definition of outcomes, inclusion criteria, risk factors and statistical considerations can cause substantial differences when pooling data, and may constitute the major causes of heterogeneity found in the current meta-analysis. Our results are consistent with those addressed in an overview published in 2003 [7]. The high efficacy of chemotherapy in inducing remission of ALNHL would increase the number of subjects in clinical trials evaluating the role of consolidative RT. Thus, all included trials were individually underpowered to assess improvement of response rate, PFS and OS.

More recently, rituximab has been incorporated into the treatment of patients with NHL, with clear benefits in PFS and OS $[37,38]$. Now the combination of rituximab with a CHOP-based chemotherapy regimen has been considered as the standard treatment for aggressive NHL patients. There is still no prospective trial evaluating the role of RT in the era of targeted therapy, so far the role of radiation after chemotherapy plus rituximab remains speculative. Recently, a retrospective study suggested improvement in both OS and PFS with consolidative RT after rituximab-CHOP chemotherapy. This improvement occurred in both early (I and II) and advanced stage (III and IV) [42]. Despite these gains, these evidences are not sufficient to support or repel the use of consolidative RT in ALNHL. The possible interaction between rutuximab and radiation therapy makes the results of these combinations unpredictable. Thus, radiation therapy should be studied in this new context, and cannot be considered a standard of care until its benefit is proven. Some studies have recently addressed the role of radiation therapy in the management of localized disease in patients with positive Positron Emission Tomography (PET) after chemotherapy [43-45]. Radiation therapy yielded interesting survival results in this subset of patients, providing a rational selection tool for consolidative radiotherapy.

There are still many unanswered questions regarding the management of early stage aggressive NHL. The ideal chemotherapy regimen, its optimal duration, the duration of rituximab treatment, the benefits of adding RT and its dose are important issues that need further evaluation by high-quality RCT. Our systematic review suggests that RT prolongs PFS and can be considered an 
option for patients who cannot tolerate a high dose or prolonged schedule of chemotherapy. Further evaluation of RT after chemotherapy is still needed.

\section{Conclusions}

In conclusion, RT prolongs PFS, with no impact on OS. It must be considered an option for patients who cannot tolerate a high dose or prolonged schedule of chemotherapy. Further investigation of the role of RT in the era of targeted therapy is needed.

\section{Competing interests}

There are no actual or potential conflicts of interest from the authors.

\section{Author details}

'Departamento de Oncologia Clínica, Hospital de Câncer de Barretos, Barretos, Brazil. ${ }^{2}$ CEVON - Centro de Evidências em oncologia, Universidade Estadual de Campinas, UNICAMP, Campinas, Brazil. ${ }^{3}$ Departamento de Clínica Médica, Centro de Evidências em Oncologia - CEVON, Faculdade de Ciências Médicas, Universidade Estadual de Campinas - UNICAMP, Campinas, SP CEP 13083-970, Brazil.

\section{Authors' contributions}

Conception and design: LVS and ADS; Acquisition of data: all authors; Analysis and interpretation of data: all authors; Manuscript drafting: LVS, JPL and ADS; Manuscript revising: all authors; final approval of this version: all authors. All Authors read and approved the final manuscript.

\section{Funding}

The authors received no specific funding for this study.

Received: 26 October 2011 Accepted: 27 June 2012

Published: 13 July 2012

\section{References}

1. Ries L, Melbert D, Krapcho M, Stinchcomb D, Howlader N, MJ H, et al: SEER Cancer Statistics Review, 1975-2005. Journal [serial on the Internet]. 2007, Date: Available from: http://seer.cancer.gov/csr/1975_2005.

2. Parkin DM, Bray Fl, Devesa SS: Cancer burden in the year 2000. The global picture. Eur J Cancer 2001, 37(Suppl 8):S4-66.

3. Harris NL, Jaffe ES, Stein H, Banks PM, Chan JK, Cleary ML, et al: A revised European-American classification of lymphoid neoplasms: a proposal from the International Lymphoma Study Group. Blood 1994, 84(5):1361-1392.

4. Harris NL, Jaffe ES, Diebold J, Flandrin G, Muller-Hermelink HK, Vardiman J, et al: World Health Organization classification of neoplastic diseases of the hematopoietic and lymphoid tissues: report of the Clinical Advisory Committee meeting-Airlie House, Virginia, November 1997. J Clin Oncol 1999, 17(12):3835-3849.

5. NCl: National Cancer Institute sponsored study of classifications of nonHodgkin's lymphomas: summary and description of a working formulation for clinical usage. The Non-Hodgkin's Lymphoma Pathologic Classification Project. Cancer 1982, 49(10):2112-2135.

6. Nieder C, Licht T, Andratschke N, Peschel C, Molls M: Influence of differing radiotherapy strategies on treatment results in diffuse large-cell lymphoma: a review. Cancer Treat Rev 2003, 29(1):11-19.

7. Gustavsson A, Osterman B, Cavallin-Stahl E: A systematic overview of radiation therapy effects in non-Hodgkin's lymphoma. Acta Oncol 2003, 42(5-6):605-619.

8. Lee CK: Evolving role of radiation therapy for hematologic malignancies. Hematol Oncol Clin North Am 2006, 20(2):471-503.

9. Hagberg H, Pettersson U, Glimelius B, Sundstrom C: Prognostic factors in non-Hodgkin lymphoma stage I treated with radiotherapy. Acta Oncol 1989, 28(1):45-50.

10. Vaughan Hudson B, Vaughan Hudson G, MacLennan KA, Anderson L, Linch DC Clinical stage 1 non-Hodgkin's lymphoma: long-term follow-up of patients treated by the British National Lymphoma Investigation with radiotherapy alone as initial therapy. Br J Cancer 1994, 69(6):1088-1093.
11. Jones SE, Miller TP, Connors JM: Long-term follow-up and analysis for prognostic factors for patients with limited-stage diffuse large-cell lymphoma treated with initial chemotherapy with or without adjuvant radiotherapy. J Clin Oncol 1989, 7(9):1186-1191.

12. Osterman B, Cavallin-Stahl E, Hagberg H, Linden O, Lenner P: High-grade non-Hodgkin's lymphoma stage I. A retrospective study of treatment, outcome and prognostic factors in 213 patients. Acta Oncol 1996, 35(2):171-177.

13. Connors JM, Klimo P, Fairey RN, Voss N: Brief chemotherapy and involved field radiation therapy for limited-stage, histologically aggressive lymphoma. Ann Intern Med 1987, 107(1):25-30.

14. Longo DL: Combined modality therapy for localized aggressive lymphoma: enough or too much? J Clin Oncol 1989, 7(9):1179-1181.

15. Longo DL, Glatstein E, Duffey PL, Ihde DC, Hubbard SM, Fisher RI, et al: Treatment of localized aggressive lymphomas with combination chemotherapy followed by involved-field radiation therapy. $J$ Clin Oncol 1989, 7(9):1295-1302.

16. Tondini C, Zanini M, Lombardi F, Bengala C, Rocca A, Giardini R, et al: Combined modality treatment with primary $\mathrm{CHOP}$ chemotherapy followed by locoregional irradiation in stage I or II histologically aggressive non-Hodgkin's lymphomas. J Clin Oncol 1993, 11(4):720-725.

17. van der Maazen RW, Noordijk EM, Thomas J, Raemaekers JM, Meerwaldt JH: Combined modality treatment is the treatment of choice for stage I/IE intermediate and high grade non-Hodgkin's lymphomas. Radiother Oncol 1998, 49(1):1-7.

18. Aviles A, Delgado S, Ruiz H, de la Torre A, Guzman R, Talavera A: Treatment of non-Hodgkin's lymphoma of Waldeyer's ring: radiotherapy versus chemotherapy versus combined therapy. Eur J Cancer B Oral Oncol 1996, $32 B(1): 19-23$.

19. Wirth $A$ : The rationale and role of radiation therapy in the treatment of patients with diffuse large B-cell lymphoma in the Rituximab era. Leuk Lymphoma 2007, 48(11):2121-2136.

20. Lymphoid neoplasms. American Joint Committee on Cancer: AJCC Cancer Staging Manual. 6th edition. New York, NY: Springer; 2002:393-406.

21. Dickersin K, Scherer R, Lefebvre C: Identifying relevant studies for systematic reviews. BMJ 1994, 309(6964):1286-1291.

22. Verhagen AP, de Vet HC, de Bie RA, Kessels AG, Boers M, Bouter LM, et al: The Delphi list: a criteria list for quality assessment of randomized clinical trials for conducting systematic reviews developed by Delphi consensus. J Clin Epidemiol 1998, 51(12):1235-1241.

23. Jadad AR, Moore RA, Carroll D, Jenkinson C, Reynolds DJ, Gavaghan DJ, et al: Assessing the quality of reports of randomized clinical trials: is blinding necessary? Control Clin Trials 1996, 17(1):1-12.

24. Parmar MK, Torri V, Stewart L: Extracting summary statistics to perform meta-analyses of the published literature for survival endpoints. Stat Med 1998, 17(24):2815-2834.

25. Tierney JF, Stewart LA, Ghersi D, Burdett S, Sydes MR: Practical methods for incorporating summary time-to-event data into meta-analysis. Trials 2007, 8:16.

26. Deeks JJ AD, Bradburn MJ: Systematic reviews in health care: Metaanalisys in context. 2nd edition. London: BMJ Publication Group; 2001.

27. DerSimonian R, Laird N: Meta-analysis in clinical trials. Control Clin Trials 1986, 7(3):177-188.

28. Higgins JP, Thompson SG, Deeks JJ, Altman DG: Measuring inconsistency in meta-analyses. BMJ 2003, 327(7414):557-560.

29. Egger M, Davey Smith G, Schneider M, Minder C: Bias in meta-analysis detected by a simple, graphical test. BMJ 1997, 315(7109):629-634.

30. Sterne JA, Egger M, Smith GD: Systematic reviews in health care: Investigating and dealing with publication and other biases in metaanalysis. BMJ 2001, 323(7304):101-105.

31. Reyes F, Lepage E, Ganem G, Molina TJ, Brice P, Coiffier B, et al: ACVBP versus CHOP plus radiotherapy for localized aggressive lymphoma. N Engl J Med 2005, 352(12):1197-1205.

32. Miller TP, Dahlberg S, Cassady JR, Adelstein DJ, Spier CM, Grogan TM, et al: Chemotherapy alone compared with chemotherapy plus radiotherapy for localized intermediate- and high-grade non-Hodgkin's lymphoma. $N$ Engl J Med 1998, 339(1):21-26.

33. Miller T, Leblanc M, Spier C, et al: CHOP alone compared with CHOP plus radiotherapy for early stage aggressive non-Hodgkin's lymphomas: Update of the Southwest Oncology Group (SWOG) Randomized trial. Blood 2001, 98:a724. 
34. Horning SJ, Weller E, Kim K, Earle JD, O'Connell MJ, Habermann TM, et al: Chemotherapy with or without radiotherapy in limited-stage diffuse aggressive non-Hodgkin's lymphoma: Eastern Cooperative Oncology Group study 1484. J Clin Oncol 2004, 22(15):3032-3038.

35. Bonnet C, Fillet G, Mounier N, Ganem G, Molina TJ, Thieblemont C, et al: CHOP alone compared with CHOP plus radiotherapy for localized aggressive lymphoma in elderly patients: a study by the Groupe d'Etude des Lymphomes de I'Adulte. J Clin Oncol 2007, 25(7):787-792.

36. A predictive model for aggressive non-Hodgkin's lymphoma: The International Non-Hodgkin's Lymphoma Prognostic Factors Project. N Engl J Med 1993, 329(14):987-994.

37. Vose JM, Link BK, Grossbard ML, Czuczman M, Grillo-Lopez A, Gilman P, et al: Phase II study of rituximab in combination with chop chemotherapy in patients with previously untreated, aggressive non-Hodgkin's lymphoma. J Clin Oncol 2001, 19(2):389-397.

38. Coiffier B, Lepage E, Briere J, Herbrecht R, Tilly H, Bouabdallah R, et al: CHOP chemotherapy plus rituximab compared with $\mathrm{CHOP}$ alone in elderly patients with diffuse large-B-cell lymphoma. N Engl J Med 2002, 346(4):235-242.

39. Tilly H, Lepage E, Coiffier B, Blanc M, Herbrecht R, Bosly A, et al: Intensive conventional chemotherapy (ACVBP regimen) compared with standard $\mathrm{CHOP}$ for poor-prognosis aggressive non-Hodgkin lymphoma. Blood 2003, 102(13):4284-4289.

40. Andre M, Mounier N, Leleu X, Sonet A, Brice P, Henry-Amar M, et al: Second cancers and late toxicities after treatment of aggressive non-Hodgkin lymphoma with the ACVBP regimen: a GELA cohort study on 2837 patients. Blood 2004, 103(4):1222-1228.

41. Recher C, Coiffier B, Haioun C, Molina TJ, Ferme C, Casasnovas O, et al: Intensified chemotherapy with ACVBP plus rituximab versus standard CHOP plus rituximab for the treatment of diffuse large B-cell lymphoma (LNH03-2B): an open-label randomised phase 3 trial. Lancet 2011, 378(9806):1858-1867.

42. Phan J, Mazloom A, Jeffrey Medeiros L, Zreik TG, Wogan C, Shihadeh F, et al: Benefit of consolidative radiation therapy in patients with diffuse large B-cell lymphoma treated with R-CHOP chemotherapy. J Clin Oncol 2010, 28(27):4170-4176.

43. Pommier P, Dussart S, Girinsky T, Chabaud S, Lagrange JL, Nguyen TD, et al: Impact of 18 F-fluoro-2-deoxyglucose positron emission tomography on treatment strategy and radiotherapy planning for stage I-II Hodgkin disease: a prospective multicenter study. Int I Radiat Oncol Biol Phys 2011, 79(3):823-828.

44. Dorth JA, Chino JP, Prosnitz LR, Diehl LF, Beaven AW, Coleman RE, et al: The impact of radiation therapy in patients with diffuse large B-cell lymphoma with positive post-chemotherapy FDG-PET or gallium-67 scans. Ann Oncol 2011, 22(2):405-410.

45. Halasz LM, Jacene HA, Catalano PJ, Van den Abbeele AD, Lacasce A, Mauch PM, et al: Combined Modality Treatment for PET-Positive Non-Hodgkin Lymphoma: Favorable Outcomes of Combined Modality Treatment for Patients With Non-Hodgkin Lymphoma and Positive Interim or Postchemotherapy FDG-PET. Int J Radiat Oncol Biol Phys 2012, 83(5):e647-e654.

doi:10.1186/1471-2407-12-288

Cite this article as: dos Santos et al:: Is there a role for consolidative radiotherapy in the treatment of aggressive and localized Non-Hodgkin Lymphoma? A systematic review with meta-analysis. BMC Cancer 2012 12:288.

\section{Submit your next manuscript to BioMed Central and take full advantage of:}

- Convenient online submission

- Thorough peer review

- No space constraints or color figure charges

- Immediate publication on acceptance

- Inclusion in PubMed, CAS, Scopus and Google Scholar

- Research which is freely available for redistribution 